\title{
Research on Training and Motivation of Innovation Talents in State-Owned Enterprises
}

\author{
Gang Lu' ${ }^{1}$, Mingming Wang ${ }^{2}$ \\ ${ }^{1}$ State Grid Energy Research Institute, Beijing, China \\ ${ }^{2}$ State Grid Jiangxi Electric Power Company, Nanchang, China \\ Email: lugang@sgeri.sgcc.com.cn
}

Received 13 May 2015; accepted 28 June 2015; published 1 July 2015

\begin{abstract}
It is crucial to break the bondage on innovative talents growth to improve the speed and quality of reform and innovative development for state-owned enterprises. This paper has investigated the issue on training and motivation of innovative talents in state-owned enterprises. It has analyzed the root causes from the aspects of value guidance, market function and innovation cultures. Meanwhile, it has presented the transformation approach of talents training and motivation from the aspects of international competition, Chinese situation, people-oriented principle, flexible management, etc.
\end{abstract}

\section{Keywords}

Innovative Talents, Training, Motivation, Transformation

\section{Introduction}

Innovative talent is the root of creativity of state-owned enterprises, and is also the backbone force to support the enterprises to become more competitive. Particularly, in the new situation of comprehensive deepening reform, innovative talents play an increasingly significant role in adapting to the new normal of economic development, seizing the development opportunities for technological revolution and the industrial revolution, and breaking the system, theory, technology and other bottlenecks. Innovative talents are all personnel who have the creative spirits, own the creative capabilities, make innovative achievements and carry out innovative activities [1]-[5]. They may be technical staff, entrepreneurs, managers, or ordinary employees. To realize the reform, creativeness and development of state-owned enterprises in the new era, it is vital to break the shackles of the growth of innovative talents, achieve effective value management over the innovative human capital, and stimulate their creativity and dynamic vitality to the maximum degree.

\section{Difficulties on Training and Motivation of Innovative Talents}

State-owned enterprises have achieved remarkable results in the marketing of selecting and employing talents,

How to cite this paper: Lu, G. and Wang, M.M. (2015) Research on Training and Motivation of Innovation Talents in State-Owned Enterprises. Open Journal of Social Sciences, 3, 30-34. http://dx.doi.org/10.4236/jss.2015.37005 
promoting "the Recruitment Program of Global Experts", establishing the performance-oriented motivation, and extensively carrying out the targeted talent training works. For example, CSIC, China XD Group Corporation, China National Machinery Industry Corporation and other state-owned enterprises implement the policies to motivate science and technology; Commercial Aircraft Corporation of China Ltd. builds the multi-channel development systems containing management, specialties, skills and etc; China Mobile combines contribution and performance and with career development; China Hualu Group actively establishes the internal talent flow mechanism and encourages the reasonable flow and effective allocation of technological talents; FiberHome Technologies Group, Ansteel and Baosteel actively explore stock options, dividend rights and other long-term motivation. These explorations inspire the creativity, stimulate a large number of creative achievements, and show the positive effect of reform and innovation.

However, from the perspective of talents, the training and motivation of innovative talents in state-owned enterprises also have "The Qian Xuesen Question". State-owned enterprises have the institutional advantages of talents introduction. In particular, after the financial crisis in 2009 , the job competition in state-owned enterprises is more intensive than competition in foreign enterprises. However, the actual result shows that the stateowned enterprises have not shown adequate creativity. The top talents amount and value-creation capability are unmatched with the size and resources of the organization. Although there are many creative achievements, the creative ratio of originality and market performance is still low. The lack of patents and management innovative results are still obvious. Compared with world-class enterprises, most of state-owned enterprises are imitating and following those enterprises, revealing the overall strength of state-owned enterprises is big but not strong.

\section{Root Cause Analysis}

To analyze the root causes of difficulties on training and motivation mechanism of innovative talents in stateowned enterprises, it is essential to determine the hot topics, such as wheel seat phenomenon of ABC assessment mechanism, mess-style remuneration and other "secondary" issues. The methods used are not wrong. The nature of things might change with the environment. The most rooted cause may be seized through these problems.

\subsection{Short-Term Utilitarian Value Orientation}

Being affected by tenure system, business decision-makers lean towards the opinion of gaining short-term economic benefits. It is difficult for them to invest high-risk independent $R \& D$ and self transformation and innovation, which is conservative. Because of the short-term utilitarian thinking, the career goals are limited. Therefore, the talent training plan and motivation evaluation mechanism are only for current performance instead of longterm effects, resulting in the short-sighted innovation and few experts. Similarly, under the condition of excessive pursuit of ranking and award, especially the poor index assessment of transformation application and benefit contribution, the individuals are affected by title assessment, job promotion, remuneration and other factors, and the enterprises are affected by reputation and brand, resource allocation, leadership performance and other factors. The individuals and enterprises pay limited attention on creative benefits, causing the disconnection of the achievement and market and resulting in wastes.

\subsection{The Inadequate Decisive Effects of the Market in Resources Allocation}

The growth of innovative talents need dynamic business system environment. Many state-owned enterprises are the industry leaders with a dominant market position, and enterprises and employees at all levels do not have crisis awareness. Moreover, many state-owned enterprises do not thoroughly transform from administrative management to market standardized management, and have not fully established the market-oriented business logic, and resulting insufficient external pressure conduction. Generally speaking, firstly, the system has invisibly turned some state-owned enterprises into a stable cradle. The "blue-collar aristocracy" situation cannot be avoided. Secondly, due to the restriction of the total wage management system, the design and innovative motivation space of market-based motivating salary system have been greatly constrained. Most state-owned enterprises get equal pay for equal work regardless of innovation, weakening the external competitiveness of high level talents. Similarly, the configuration mechanism on innovative talents is rigid with inflexible inside and irreasonable flow, failing to make use of the talents. 


\subsection{The Lack of Innovation Encouragement on Corporate Culture}

The culture has deep impact on innovation. Under the executive-led "official standard" system and senioritybased system, talents do not have enough innovative vitality and dynamism. Most firms have built formal technical career paths, but it is difficult to form a professional development environment for scientific researchers. The planned innovation is primary. The constraint of order execution inevitably limits the spirit, courage and practice to pursue innovation. In contrast, the atmosphere of high tolerance for failure and respect, as well as relatively free environment will easily arouse the inherent innovative motivation. Google, $3 \mathrm{M}$ and $\mathrm{P} \& \mathrm{G}$ give fully authorization to the employees, encourage them to spend $20 \%, 15 \%$ and $25 \%$ of working hours respectively to try new ideas, and create the appropriate conditions to support the unplanned innovation.

\section{How to Transform}

The talent issue facing by state-owned enterprises is the epitome of the social talent issue in China. This issue cannot be completely resolved simply by optimizing the remuneration, assessment, training and other mechanisms by any company itself. The innovative talents development can only be promoted by changing the overall system of talent selection and training as well as reforming the management system of state-owned enterprises. China is comprehensively deepening the reforms and improving the governance system, and thus the training and motivation system of innovative talents in state-owned enterprises will be improved gradually. However, the system reform cannot be settled in one step. The ancient Chinese talent selection has gone through a long historic change. If the external reform has created precondition, the internal reform should been kept up; if the external reform has not be taken, the internal reform should be made through self-revolution. In this long process, the following issues should be concerned [3]-[7].

\subsection{Global Vision}

Accurately grasp the national talent strategy and plan the talent works with a global vision. China vigorously implements the innovative-driven development strategy, accelerates and restructures from Made in China to Created in China. The demand for international talents is urgently increasing, so talent attraction and recruitment have become an important factor affecting the development speed and quality of innovation. At the same time, the global talent competition is increasingly fierce, posing a huge challenge for China to participate in international talent competition. State-owned enterprises, with special position and advantages, should take the responsibilities as a main force in international talent competition. At the new development stage of globalization and "going out" strategy, state-owned enterprises should build an open talent system with a more inclusive mind, select and introduce the global talents. It is not only the obligation for state-owned enterprises but also a historical opportunity.

\subsection{Taking Our Own Way Firmly}

The national condition of China is important for business management. The innovative development paths for both state-owned and private enterprises are significantly different from foreign companies. The problems and solutions have Chinese characteristics. For the motivation and training of innovative talents in state-owned enterprises, it is essential to understand the features and conditions of Chinese state-owned enterprises, so only using western management models or advanced business human resources development method may not necessarily work. The essence of Toyota's Lean Management is that employees spontaneously make improvements. This has deep cultural imprint which may not applicable for another country. Therefore, Chinese enterprises must conduct talent training and motivation by integrating with own features. Western selection and retaining system is not omnipotent, namely, changing from a nonstandard enterprise into a $\mathrm{d}$ regular enterprise. For the next step, Chinese enterprises should gradually and confidently formed its own features.

\subsection{People-Oriented Principle}

Stick to the principle of human capital appreciation strategically, clarify the priority position of human resource development and investment, accelerate to transform the business concept of giving priority to physical capital instead of human capital, incorporate human capital into total capital operation, and promote the talent devel- 
opment. From strategy perspective, take human resources as the first resource. It is necessary to first transform to creative human resource system, motivate the active resources, and drive efficient configuration of other resources. From concept perspective, by believing that everyone is a potential resource for innovation, the enterprises might release the creative opportunities and resources fairly and generally. Without wearing tinted glasses, the enterprises can truly and fundamentally realize the respect for humanity, and gradually form an environment favorable for innovative talents growth.

\subsection{Flexible Management}

Implement the flexible management by stimulating the subjective initiative of talents and exploring the potential creativity. To develop innovative human resource capital, the starting point is guidance instead of control, and the focus is to comply with the characteristics of innovative talents by stimulating the motivation and satisfying the senses of accomplishment. While in the management, the structure of the enterprises should be flatter and the power should be decentralized within measure. Balance the supervision and freedom, and promote to develop the contracting relationship to federal relationship between talents and enterprises. In decision making, be democratic and open, transit to governance from top to bottom, advocate different thoughts, respect the grassroots initiation, and help the employee meet their own goals. In organizational environment, ensure the fairness, insist the orientation of value creation, strengthen the decisive role of market in the human resource allocation, select through competition, change seniority-based system and egalitarian culture, achieve "competency-based" and "performance-based" talent selection.

\subsection{Adjust Measures to Talents}

Seize the characteristics of innovative talents and adjust measures to them. Innovative human capital has unique characteristics of value creation capability and self-realization demand. Therefore, the motivation target should be long-term. Focus on the competitive product, independent brand strategy and world-class business goals, set up the challenging career vision for various innovative talents, and provide the self-challenge job objectives; accelerate to train talents who can seize the strategic opportunity, realize the continuous improvement of human capital self-value creativity by building the study-oriented organization; integrate the material motivation, target motivation and mental motivation, transform the sustainable motivation to entrepreneurial motivation, and extremely release the innovative energy.

\subsection{Differential Demands inside the Organization}

Develop targeted strategies for difficulties faced by innovative talents in all levels of organization. Due to inadequate resources, administrative-order intervention and strict system, it is important to effectively transfer the market pressure, achieve duty-right matching, give space to creativity, and stimulate vitality. For example, "Integrating Order with Personnel" model of Haier Group has greatly stimulated the creativity of front-line staff. Perhaps the biggest embarrassment of the upper organization is "talent absence"; the innovative talents at this level should be leaders, so it is necessary to select talents through competition by internal training and external attraction. Strengthen their strategic literacy, theoretic literacy and command literacy, stimulate the potentials to promote the production and management idea, implement the reform, lead global R \& D, and build up the lead of state-owned enterprises.

\section{Conclusion}

Currently, China is in the middle of realizing the "two-century" objective, which is the common task of the whole nation, including state-owned enterprises. In the intersection of the past and the future, under the circumstances of economic and social transformation whether in domestic or overseas, the scale and quality of innovative talents will be a decisive factor affecting the innovation development. We are bound to deepen the reform firmly by applying people-oriented principle to creative a sound environment for talent growth.

\section{References}

[1] Guo, S.T. (2012) Research on Contemporary Chinese Innovative Talent Development. Shandong University. 
[2] Tu, M.J., Tang, Y., Zhang, J. and Meng, J.P. (2012) Thoughts, Methods and Pathways on Innovative Talents Cultivation (One). Journal of Xihua University (Natural Science Edition), 31.

[3] Shang, G.J. (2014) Based on The Innovative Human Capital Value Chain Model. Hainan University.

[4] Li, N. (2013) Training Strategy for Innovative Talents. Value Engineering.

[5] Li, Q.W. and Yan, J.D. (2012) Analysis of Influence Factors of Enterprise Innovation Talents. Pioneering with Science \& Technology Monthly.

[6] Zhang, X. (2013) The Research of Incentive Factors of State-Owned Enterprises, Innovation and Institution Design. Hefei University of Technology.

[7] Wang, Y. (2011) China's State-Owned Enterprise Management Innovation Characteristics and Mechanism of Power in Economic Restructuring Time. Jiangsu University. 